\title{
Dynamic Expansion of Gastric Mucosal Doublecortin-Like Kinase 1-Expressing Cells in Response to Parietal Cell Loss Is Regulated by Gastrin
}

\author{
Eunyoung Choi, ${ }^{* \dagger \ddagger}$ Christine P. Petersen, ${ }^{* \dagger \S}$ Lynne A. Lapierre, ${ }^{* \dagger}$ Janice A. Williams, ${ }^{*}$ Victoria G. Weis, ${ }^{* \dagger \S}$ \\ James R. Goldenring, ${ }^{* \dagger \delta 币}$ and Ki Taek Nam*\|**
}

\begin{abstract}
From the Section of Surgical Sciences, ${ }^{*}$ the Epithelial Biology Center, ${ }^{\dagger}$ the Department of Cell and Developmental Biology, ${ }^{\S}$ and the Vanderbilt-Ingram Cancer Center, ${ }^{\top}$ Vanderbilt University School of Medicine, Nashville, Tennessee; the Nashville VA Medical Center, ${ }^{\ddagger}$ Nashville, Tennessee; and the Severance Biomedical Science Institute" and the Brain Korea 21 PLUS Project for Medical Science, ** Yonsei University College of Medicine, Seoul, Republic of Korea
\end{abstract}

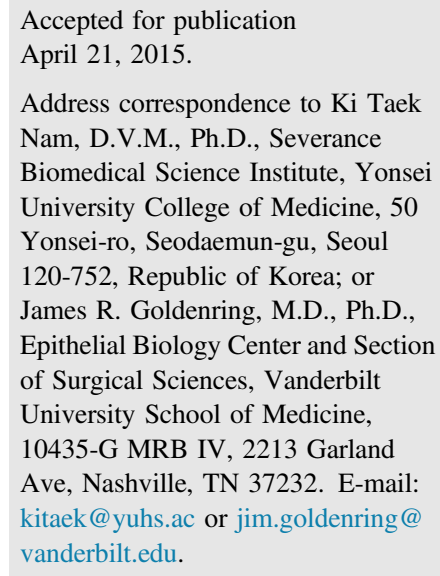

\begin{abstract}
Doublecortin-like kinase 1 (Dclk1) is considered a reliable marker for tuft cells in the gastrointestinal tract. We investigated the dynamic changes of tuft cells associated with mouse models of oxyntic atrophy and metaplasia in the stomach. Increases in the numbers of Dclk1-positive tuft cells were observed in several models of parietal cell loss. However, the expanded population of Dclk1-expressing cells showed a morphologically distinct structure in apical microvilli and acetylated microtubules, which was not seen in the tuft cells present in the normal gastric mucosa. These microvillar sensory cells (MVSCs) showed no evidence of proliferation. The expansion of the MVSCs induced by oxyntic atrophy was reversible after the return of parietal cells. More important, expansion of MVSCs after induced parietal cell loss was not observed in $\mathrm{Gast}^{-/-}$mice. Although the Dclk1-expressing cells in the normal gastric mucosa were in part derived from Lrig1-expressing stem cells, the Lrig1-lineaged cells did not produce the expanded Dclk1-expressing cells associated with oxyntic atrophy. These studies indicate that loss of parietal cells leads to the reversible emergence of a novel Dclk1-expressing sensory cell population in the gastric mucosa. (Am J Pathol 2015, 185: 2219-2231; http://dx.doi.org/10.1016/j.ajpath.2015.04.009)
\end{abstract}

Tuft cells, also known as brush or caveolated cells, represent an unusual type of epithelial cell present in multiple organs of the digestive system, including the stomach and the intestine. ${ }^{1-3}$ Tuft cells are rare in the epithelial cell layer and are characterized by the presence of a luminally directed tuft, which displays a distinct membrane-covered array of microtubules. The presence of the apical tuft apparatus suggests that tuft cells have functions for detection and transmission of environmental signals. ${ }^{4}$ Tuft cells represent a class of solitary chemosensory cells, because they express several chemoreceptor molecules, such as the guanine nucleotide binding protein $\alpha$-transducing 3 and the G-protein-coupled taste receptor type 1 member $3 .^{5}$ Although tuft cells are continuously renewed in the epithelial cell layer, mitotic tuft cells have not been observed. These findings suggest that tuft cells are post-mitotic and might originate from other sources.

\footnotetext{
Supported by a Vanderbilt Digestive Disease Research Center Pilot Project grant NIH P30 DK058404, Yonsei University College of Medicine for 2013 faculty research grant 6-2013-0061 and new faculty research seed money grant 2013-32-0031, Korea Mouse Phenotyping Center and the Brain Korea 21 PLUS Project for Medical Science, Yonsei University, the Bio and Medical Technology Development Program of the National Research Foundation (NRF), funded by the Ministry of Science, ICT and Future Planning grant NRF-2013M3A9D5072551, and Basic Science Research Program through the NRF, funded by the Ministry of Education grant 2014R1A1A2058389 (K.T.N.); a Department of Veterans Affairs Merit Review grant 1BX000930 and NIH grants RO1 DK071590, R01 DK101332, and R24 DK096527 (J.R.G.); and the core resources of the Vanderbilt Digestive Disease Center grant P30 DK058404 and the Vanderbilt-Ingram Cancer Center through National Cancer Institute Cancer Center support grant P30 CA068485 using the Translational Pathology Shared Resource, The Vanderbilt University Medical Center (VUMC) Cell Imaging Shared Resources, the Electron Microscopy Shared Resource, and the Chemical Synthesis Shared Resource. These studies used Ariol SL-50 imaging in the VUMC Digital Histology Shared Resource.

Disclosures: None declared.
} 
A

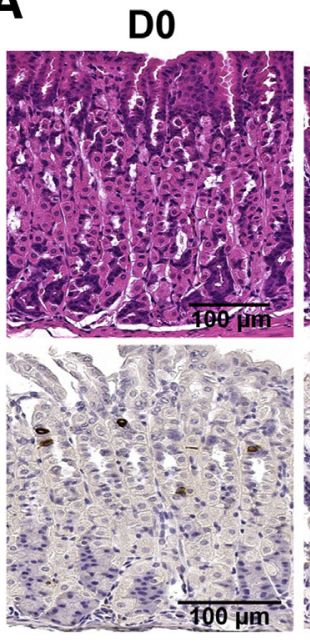

B

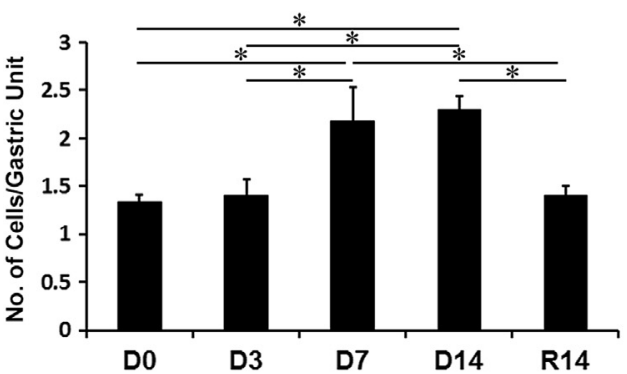

D3
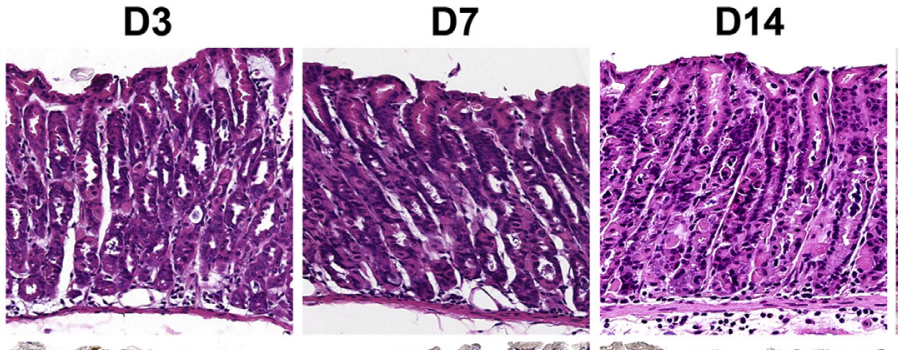

(20)

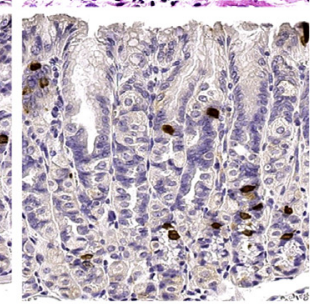

R14
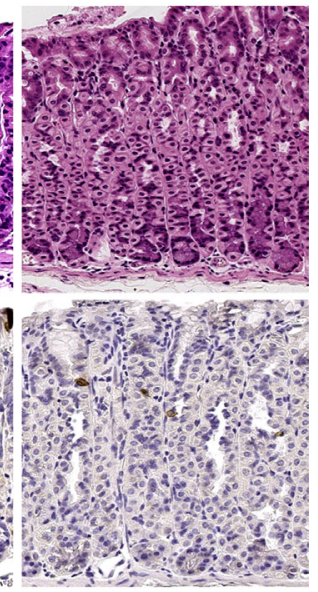

\section{C}

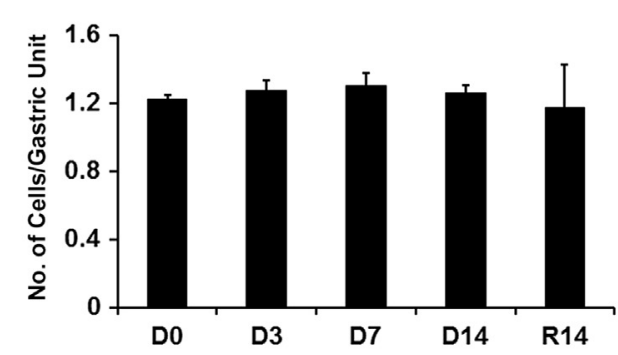

Figure 1 Immunohistochemistry of doublecortin-like kinase 1 (Dclk1) in DMP-777-treated mouse stomachs. A: Hematoxylin and eosin-stained stomachs from untreated wild-type mice (D0) or wild-type mice treated with DMP-777 for 3, 7, and 14 days (D3, D7, and D14, respectively) and after withdrawal of DMP-777 for 14 days (R14). Sections of the oxyntic glands were immunostained with antibodies against Dclk1 from D0, D3, D7, D14, and R14. B and C: Quantitation of Dclk1-expressing cells in wild-type mice with or without DMP-777 treatment in the fundus (B) and the antrum (C). The graphs present the number of Dclk1-expressing cells per Dclk1-positive gland. Cells were counted in 50 glands per mouse. ${ }^{*} P<0.05$ between groups. $N=4$ mice (B and C).

In the intestine, a recent report has suggested that tuft cells may differentiate from Leucine-rich repeat-containing Gprotein coupled receptor 5 (Lgr5)-positive progenitor cells. ${ }^{6}$ However, no Lgr5-positive stem cells are present in the body of the stomach, so the identity of cells that can produce or differentiate into tuft cells in the stomach fundus is unclear.

Recent studies have reported that doublecortin-like kinase (Dclk1)-expressing cells are present in populations of migrating and post-mitotic neurons and in radial glia cells, known as precursors of neural stem cells. ${ }^{7}$ Dclk1-expressing cells are also proposed as stem/progenitor cells in the organs of the gastrointestinal tract, ${ }^{8}$ and Dclk1 is also present in gastric tuft cells. ${ }^{1,3}$ We and several other groups have found that Dclk1-expressing cells are a rare cell lineage in the mouse stomach, ${ }^{1,9}$ and the gastric Dclk1-expressing cells appear to represent tuft cells, rather than a stem/progenitor cell population. ${ }^{1}$ We have also reported that Dclk1expressing tuft cells are found in association with invasive neoplastic lesions from the forestomach or glandular transition zone in the Smad3-null mouse stomachs. ${ }^{9}$ Although the Dclk1-expressing cells were highly expanded during gastric tumor progression in the fundic glands of Smad3-null mouse stomach, the Dclk1-expressing cells were not increased in the antrum. Although we did observe a marked increase in Dclk1-positive tuft cells in association with parietal cell loss and the development of spasmolytic polypeptideexpressing metaplasia (SPEM), the precise origin of Dclk1expressing cells in the stomach remains largely unknown.

Herein, we hypothesized that the number of Dclk1expressing cells may be increased in association with parietal cell loss. We investigated the dynamics of Dclk1expressing cells in several mouse models of oxyntic atrophy using acute treatment with DMP-777 or L-635, which are parietal cell-specific protonophores and initiate SPEM after acute parietal cell loss, ${ }^{10-12}$ and Helicobacter felis infection, a chronic model of SPEM with a strong inflammatory response. ${ }^{13} \mathrm{We}$ also examined a model of spontaneous parietal cell loss and metaplasia in the Areg ${ }^{-1-}$ mouse, which is a unique mouse model for the induction of SPEM and progression of SPEM to intestinal metaplasia. ${ }^{14}$ Finally, we compared these findings with oxyntic atrophy and SPEM induced in insulin-gastrin (INS/GAS) transgenic mice ${ }^{13}$ as well as Gast $^{-/-}$mice, which demonstrate rapid induction of SPEM after 1 day of DMP-777 treatment. ${ }^{12}$ In addition, we sought to identify the lineage of origin for tuft cells in the stomach using defined lineage 

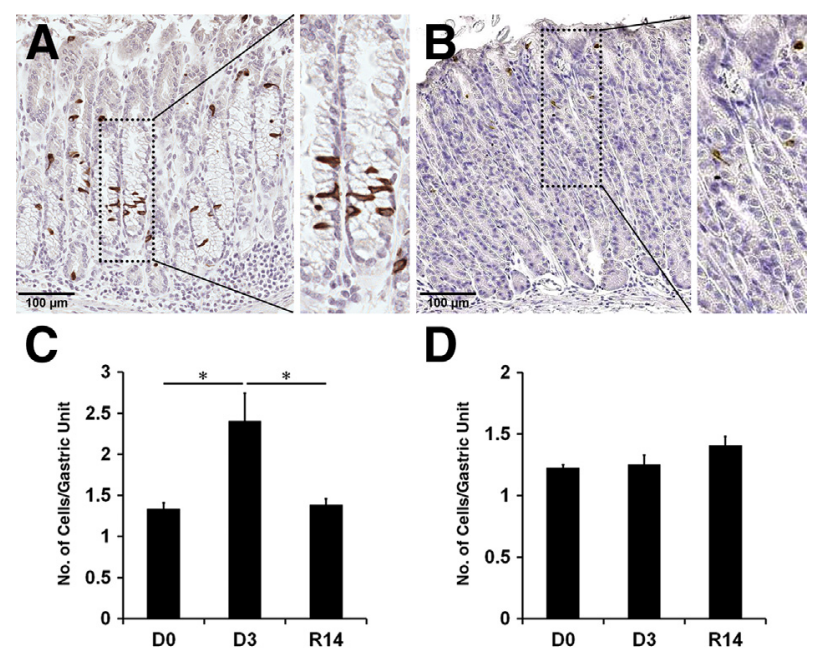

D

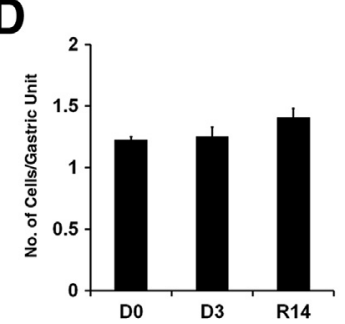

Figure 2 Immunohistochemistry of doublecortin-like kinase 1 (Dclk1) in L-635-treated mouse stomachs. A and B: The oxyntic glands were immunostained with antibodies against Dclk1 in sections of wild-type mice treated with L-635 for 3 days (A) or after withdrawal of L-635 for 14 days (B). Boxed areas depict regions enlarged. C and D: Quantitation of Dclk1expressing cells in wild-type mice (D0) compared with L-635 treatment for 3 days (D3) and after withdrawal of L-635 for 14 days (R14) in the fundus (C) and the antrum (D). The graphs present the number of Dclk1-expressing cells per Dclk1-positive gland. Cells were counted for 50 glands per mouse. ${ }^{*} P<0.05$ between groups. $N=3$ to 5 mice $(\mathbf{C}$ and $\mathbf{D})$.

mapping mouse strains. The results suggest that Dclk1expressing cells are amplified in the setting of parietal cell loss and that the increase in tuft cells is driven by elevations in gastrin. More important, the Dclk1-expressing cells are rapidly lost from the mucosa on reestablishment of parietal cells and normal gastric lineages. These transiently presenting Dclk1-positive cells have a morphology that is distinct from normal tuft cells, suggesting that they represent a distinct class of sensory cells.

\section{Materials and Methods}

\section{Mouse Models and Mice Treatment}

Preparation and treatment of mice with L-635, DMP-777, and H. felis have been described previously. ${ }^{10-12}$ Briefly, mice were administered L- 635 or DMP- 777 orally as a gavage $(350 \mathrm{mg} / \mathrm{kg}$ per day) once daily for 3 days (L-635) or for 14 days (DMP777). Mice were fasted overnight before $H$. felis infection, and H. felis was delivered by orogastric lavage in $500 \mu \mathrm{L}$ of cell suspension of $1 \times 10^{9}$ colony-forming units $/ \mathrm{mL}$ three times, every other day. Colonization of mice with $H$. felis was confirmed as previously described. ${ }^{15}$ The generation of $\mathrm{Areg}^{-1-}$ mice, INS/GAS transgenic mice, Gast $^{-\perp}$ mice, Wnt1 ${ }^{\mathrm{CreER} /+}$ mouse, Mist1 $1^{\text {CreER/+ }}$ mice, Lgr5 $5^{\text {EGFP-IRES-creERT2/+ }}$ mice, Lrig $1^{\text {CreERT2/+ }}$ mice, $R 26 R^{\text {LacZ }}$ mice, and $R 26 R^{\text {eYFP }}$ mice has been described previously. ${ }^{12,13,16-22}$ The Mist ${ }^{\text {CreERT2/+ }}$; $R 26 R^{\text {eYFP }}$, Atp $4 \mathrm{~b}^{\text {CreERT2/+ }}$, Lgr $5^{\text {EGFP-IRES-creERT2/+ }} ; R 26 R^{\text {LacZ, }}$ and Lrig ${ }^{\text {CreERT2/+ }} ; R 26 R^{\text {eYFP }}$ mice were treated with either 3 days of L-635 or 14 days of DMP-777 at 10 days after tamoxifen treatment. The care, maintenance, and treatment of mice used in this study followed protocols approved by the Institutional Animal Care and Use Committee of Vanderbilt University (Nashville, TN).

\section{Immunochemistry and Three-Dimensional SIM}

The following primary antibodies were used for immunohistochemistry and immunofluorescence. Rabbit anti-Dclk1 (1:1000 or 1:3000 dilution; Abcam, Burlingame, CA), mouse anti-5-bromo-2'-deoxyuridine (BrdU; 1:100 dilution; Calbiochem, San Diego, CA), rabbit anti-green fluorescent protein (GFP)/yellow fluorescent protein (YFP; 1:500 dilution; Novus, Littleton, CO), Alexa Fluor 594 ConjugatedLectin GS-II (1:1500 dilution; Invitrogen, Paisley, UK), mouse anti-acetylated tubulin (1:1000 dilution; SigmaAldrich, St. Louis, MO), rabbit anti-Sox9 (1:500 dilution; Santa Cruz, Dallas, TX), and rabbit anti-epidermal growth factor receptor (EGFR; phospho-Y1092; 1:500 dilution; Abcam). Mouse stomach sections were deparaffinized and submitted to antigen retrieval in the Target Retrieval solution (Dako North America, Inc., Carpinteria, CA) using a pressure cooker. Primary antibodies were incubated at $4^{\circ} \mathrm{C}$ overnight. For immunohistochemistry, secondary antibody incubation and diaminobenzidene development were performed using the Dako Envision + System-HRP DAB (Dako North America, Inc.). For immunofluorescence, secondary antibodies conjugated with Alexa 488, Cy3, or Cy5 were
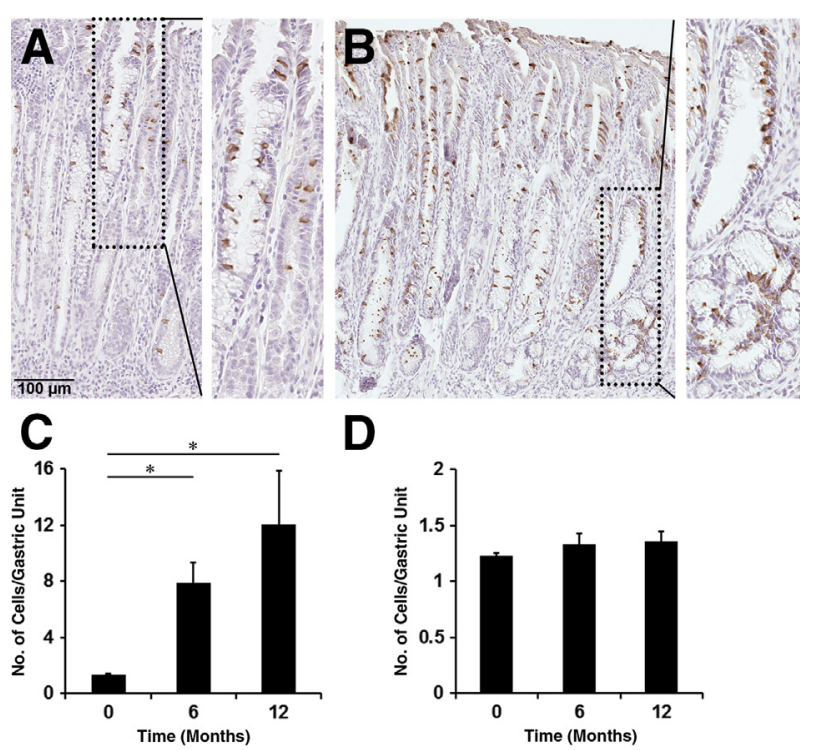

D

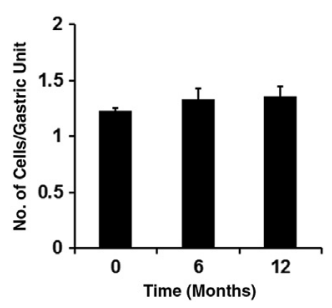

Figure 3 Immunohistochemistry of doublecortin-like kinase 1 (Dclk1) in Helicobacter felis-infected mouse stomachs. A and B: Fundic glands were immunostained with antibodies against Dclk1 in sections of wild-type mice infected with $H$. felis for 6 months (A) or for 12 months (B). Boxed areas depict regions enlarged. $\mathbf{C}$ and $\mathbf{D}$ : Quantitation of Dclk1-expressing cells in untreated wild-type mice and $H$. felis-infected wild-type mice in the fundus (C) and the antrum (D). The graphs present the number of Dclk1-expressing cells in a single Dclk1-positive gland. Cells were counted for 50 glands per mouse. ${ }^{*} P<0.05$ between groups. $N=3$ to 4 mice (C and $\left.\mathbf{D}\right)$. 

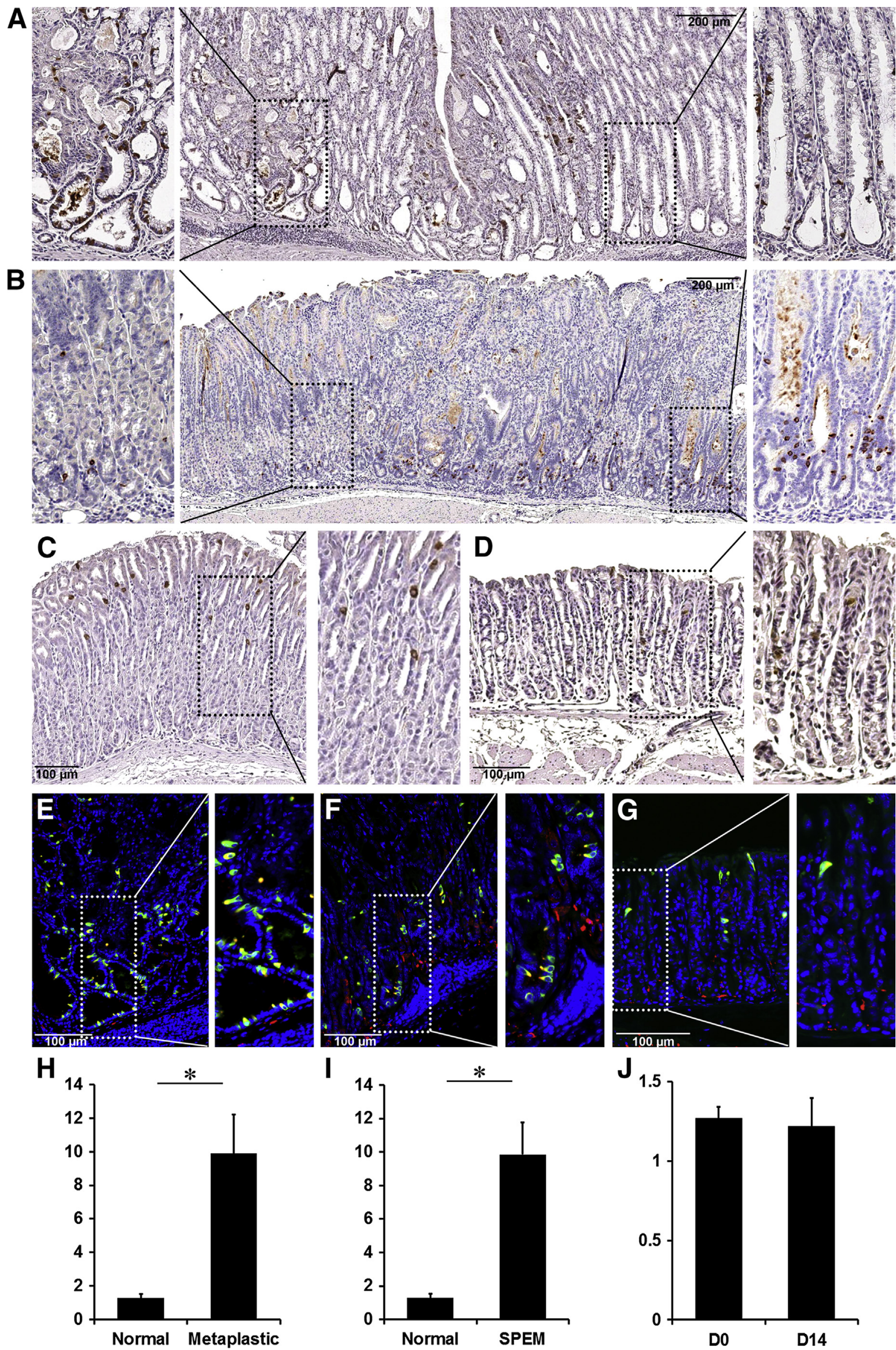
incubated at room temperature for 1 hour. For dual labeling of rabbit anti-GFP/YFP and rabbit anti-Dclk1 antibodies, we used the Tyramide Signal Amplification-Plus Fluorescein Kits (PerkinElmer, Waltham, MA) to detect the GFP/YFP primary antibody (1:5000 dilution). After washes with $1 \times$ phosphate-buffered saline and a second blocking step, we incubated with the Dclk1 primary antibody, which was then detected using Cy3-conjugated secondary antibody. Fluorescence imaging was performed on an Axio Imager 2 microscope (Carl Zeiss AG, Oberkochen, Germany). Tissues for structured illumination microscopy (SIM) imaging were stained as for immunofluorescence staining, imaging was performed on a DeltaVision OMX microscope (Applied Precision Inc., Mississauga, ON, Canada) through OMX software, and a Linux workstation with sortWorX software version 6.1.3 was used for reconstruction of threedimensional SIM images.

\section{Transmission Electron Microscopy}

Stomach tissues were prepared and observed by the Vanderbilt Cell Imaging Shared Resource, Vanderbilt University. Briefly, stomachs from wild-type or L-635-treated mice were washed in $0.1 \mathrm{~mol} / \mathrm{L}$ cacodylate buffer. The tissues were fixed in scanning electron microscopy buffer (2\% paraformaldehyde, $3 \%$ glutaraldehyde, and $0.1 \mathrm{~mol} / \mathrm{L}$ cacodylate buffer) at room temperature for 1 hour, then at $4^{\circ} \mathrm{C}$ for 4 days. Tissues were washed with $0.1 \mathrm{~mol} / \mathrm{L}$ cacodylate buffer at room temperature for 10 minutes, treated with $2 \%$ osmium tetroxide in $0.1 \mathrm{~mol} / \mathrm{L}$ cacodylate buffer for 1 hour at room temperature, and washed with $0.1 \mathrm{~mol} / \mathrm{L}$ cacodylate buffer for 10 minutes at room temperature, then with distilled water for 10 minutes at room temperature. Tissues were dehydrated through a graded ethanol series (30\% to 100\%). The tissues were incubated for 5 minutes in $100 \%$ ethanol and propylene oxide (PO), followed by two exchanges of pure PO. The tissues were infiltrated with Epon 812 resin (Electron Microscopy Sciences, Hatfield, PA) and PO (1:3) for 30 minutes at room temperature, and then infiltrated with Epon 812 resin and PO (1:1) for overnight at room temperature. Next day, the samples went through a resin:PO (3:1) exchange for 3 to 4 hours, and then were incubated with pure epoxy resin overnight. The next day, the tissues were incubated in two more changes of pure epoxy resin, then allowed to polymerize at $60^{\circ} \mathrm{C}$ for 48 hours. Ultrathin sections (70 to $80 \mathrm{~nm}$ thick) were cut and collected on 300 -mesh copper grids. The sections were stained with $2 \%$ uranyl acetate and then with Reynold's lead citrate. The tissues were observed using a Philips/FEI T-12 Tecnai T12 electron microscope (Vanderbilt Cell Imaging Shared Resource, Vanderbilt University, Nashville, TN).

\section{Statistical Analysis}

The number of Dclk1-expressing cells was compared between normal and DMP-777, L-635, and H. felis-treated mouse stomachs using a one-way analysis of variance with a post hoc comparison of groups with a Bonferroni multiple comparison test. For all comparisons, $P<0.05$ was considered statistically significant.

\section{Results}

\section{Reversible Expansion of Dclk1-Expressing Cells in Acute 0xyntic Atrophy Mouse Models}

To examine whether the induction of metaplasia by acute oxyntic atrophy is associated with emergence of Dclk1expressing tuft cells, we investigated the expression of Dclk1 in mice treated with either DMP-777 or L-635 for induction of acute oxyntic atrophy without or with the presence of inflammation, respectively. ${ }^{10-12}$ Treatment with DMP-777 in normal mice leads to rapid loss of parietal cells from the fundic mucosa, followed by the emergence of SPEM without inflammation after 7 to 14 days of treatment (Figure 1A). ${ }^{12}$

After DMP-777 treatment in C57BL/6 mice for 3, 7, and 14 days, we investigated the changes of Dclk1-expressing cells (Figure 1A). In the fundic glands of untreated mice, a few Dclk1-positive cells were located in the neck-isthmus region of the glandular units. However, the number of Dclk1-expressing cells was significantly increased in the fundic mucosa by 7 and 14 days of DMP-777 treatment (Figure 1B), but no changes were observed in the antrum (Figure 1C). After withdrawal of DMP-777 for 14 days, the fundic glands reacquired their normal compendium of parietal cells. Surprisingly, the number of Dclk1-expressing cells after withdrawal of DMP-777 decreased to the level in untreated mice and the pattern of Dclk1-expressing cells returned to the distribution observed in untreated mice (Figure 1).

We also examined the expression of Dclk1 in a second acute oxyntic atrophy and SPEM model with inflammation induced by L-635 treatment for 3 days (Figure 2 and Supplemental Figure S1). The Dclk1-expressing cells were scattered throughout the fundic glands with SPEM and increased twofold compared with untreated mice (Figure 2, A

\footnotetext{
Figure 4 Immunohistochemistry of doublecortin-like kinase 1 (Dclk1) in metaplastic mouse stomachs. A and B: Sections of the fundic mucosa from amphiregulin (AR) knockout mouse stomachs (A) or insulin-gastrin (INS/GAS) transgenic mouse stomachs (B) were immunostained with antibodies against Dclk1. C and D: Sections of the fundic mucosa from Gast ${ }^{-1}$ - mouse stomachs (C) or Gast ${ }^{-1-}$ mouse stomachs after DMP-777 treatment for 14 days (D) were immunostained with antibodies against Dclk1. E and F: Section of the fundic mucosa from Areg $^{-1-}$ mouse stomachs (E), INS/GAS transgenic mouse stomachs $(\mathbf{F})$, and Gast ${ }^{-/}$mouse stomachs after DMP-777 treatment for 14 days (G) were immunostained with antibodies against Dclk1 (green) and acetylated tubulin (red). Nuclei were counterstained with DAPI (blue). Boxed areas depict regions enlarged. $\mathbf{H}$ and $\mathbf{J}$ : The graphs present the number of Dclk1-expressing cells per Dclk1-positive gland unit. Cells were counted for 15 glands per mouse. ${ }^{*} P<0.05$ between groups. $N=4$ mice $(\mathbf{H}-\mathbf{J})$.
} 

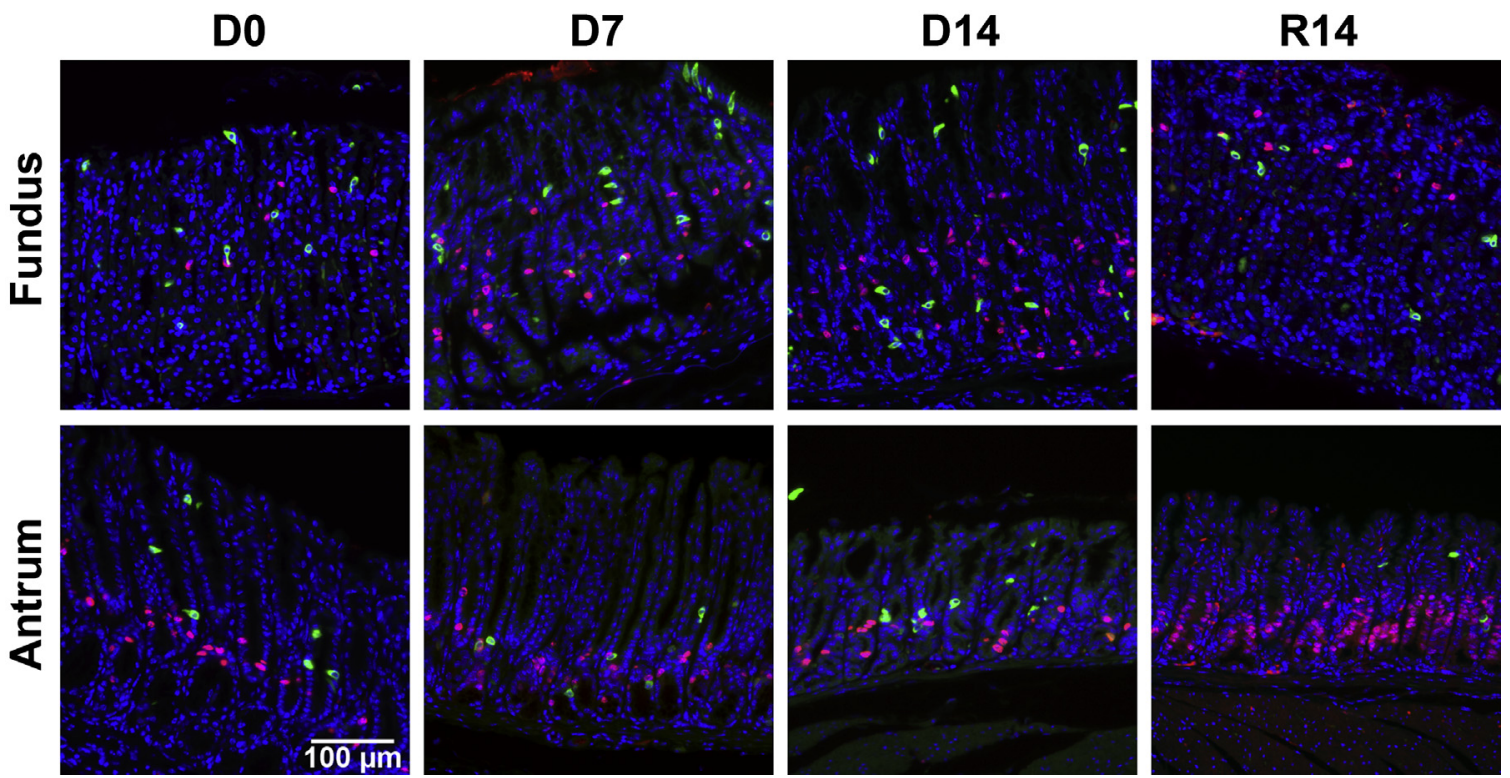

Figure 5 Immunofluorescence staining for doublecortin-like kinase 1 (Dclk1)-expressing cells and proliferating cells in the mouse stomachs. 5-Bromo-2'deoxyuridine (BrdU) was administered to wild-type mice treated without or with DMP-777 for 7 and 14 days (D7 and D14, respectively), and after withdrawal of DMP-777 for 14 days (R14). Sections of the fundic and antral glands were immunostained with antibodies against Dclk1 (green) and BrdU (red). No Dclk1-expressing cells were copositive for BrdU.

and $\mathrm{C}$ ), but no increases were observed in the antral glands (Figure 2D). Similar to our findings with DMP-777 treatment, we observed significant decreases in the Dclk1-expressing cells after withdrawal of L-635 for 14 days (Figure 2B). These results indicate that Dclk1-expressing cells increase in association with parietal cell loss and the emergence of SPEM, but the changes in Dclk1-expressing cell numbers are rapidly reversed in concert with the recovery from the parietal cell loss.

\section{Dclk1-Expressing Cells Increase in Metaplasia Associated with Chronic Inflammation and Neoplasia}

To evaluate whether Dclk1-expressing cells are also altered under other preneoplastic conditions associated with chronic inflammation, oxyntic atrophy, and SPEM, we examined the presence of Dclk1-expressing cells in $\mathrm{H}$. felis-infected mice. At both 6 months and 1 year, H. felis-infected mice showed a large increase of Dclk1-expressing cells in the fundic mucosa within areas with SPEM (Figure 3, A and B). We observed Dclk1-expressing cells throughout the glands with SPEM, but more Dclk1-expressing cells were located in the neck and surface area. Although 1.34 Dclk1expressing cells per gland were observed in the normal fundus (Figure 3, C and D, and Supplemental Figure S2), 7.87 Dclk1-expressing cells per gland were detected in the fundus from mice with $\mathrm{H}$. felis infection (Figure 3C). Interestingly, Dclk1-expressing cells were still observed in mice 12 months after $H$. felis infection, and the cell number was increased ninefold higher than in the normal gastric mucosa. However, the Dclk1-expressing cell numbers remained unchanged in the antrum in $\mathrm{H}$. felis-infected mice (Figure 3D). This result indicates that Dclk1-expressing cells also increased in the metaplastic mucosa associated with chronic inflammation.

Because our previous study showed that Dclk1expressing cells increase in gastric tumors of Smad3deficient mice ${ }^{9}$ and we also observed Dclk1-expressing cell expansion after 12 months of $H$. felis infection, we investigated whether Dclk1-expressing cells also increase in other mouse models, which develop atrophy and SPEM. First, we examined Dclk1-expressing cells in the $\mathrm{Areg}^{-1-}$ mice, which develop oxyntic atrophy, SPEM, and gobletcell intestinal metaplasia by 18 months of age. ${ }^{14}$ Figure 4, A and $\mathrm{H}$, shows an area of fundic metaplasia and dysplasia in an 18-month-old $\mathrm{Areg}^{-/-}$mouse stomach. We detected many Dclk1-expressing cells at the bases of the invasive metaplastic fundic glands and in cystic lesions (Figure 4A). The expanded Dclk1-expressing cells colocalized with acetylated tubulin, indicating their identity as tuft cells (Figure 4D).

We next examined the changes of Dclk1-expressing cells in INS/GAS transgenic mouse stomachs (Figure 4B). INS/GAS mice show moderate hypergastrinemia and over time the mice develop oxyntic atrophy, SPEM, and eventually gastritis cystica profunda. ${ }^{13}$ We detected significantly increased Dclk1-expressing cells in regions of SPEM (Figure 4, B and I), and the Dclk1-expressing cells colocalized with acetylated tubulin (Figure 4E). In contrast, Dclk1 did not increase in regions with normal glands, which still contained parietal cells (Figure 4B).

Given the increase in tuft cells in INS/GAS mice, we next sought to examine the changes of Dclk1-expressing cells in the Gast $^{-1-}$ mice. Our previous studies have shown that DMP-777 treatment is associated with rapid increases in serum gastrin. ${ }^{12}$ Although DMP treatment elicited SPEM 
A

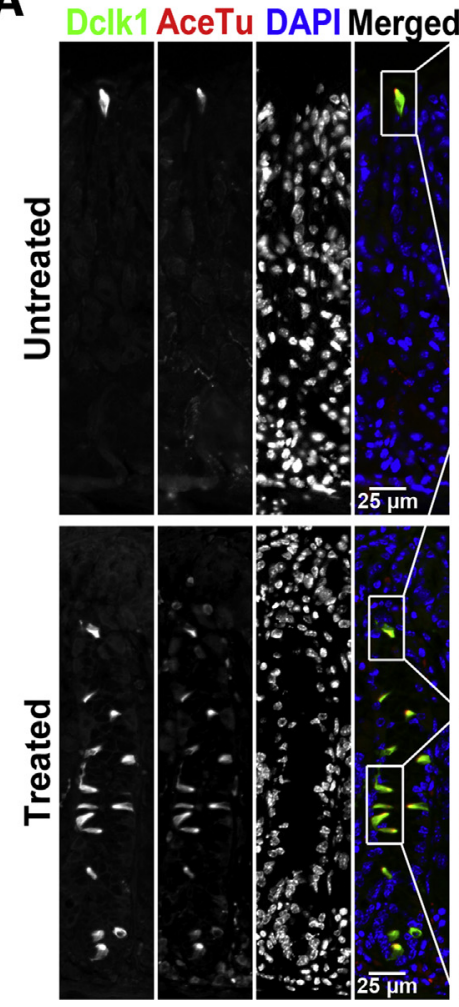

B
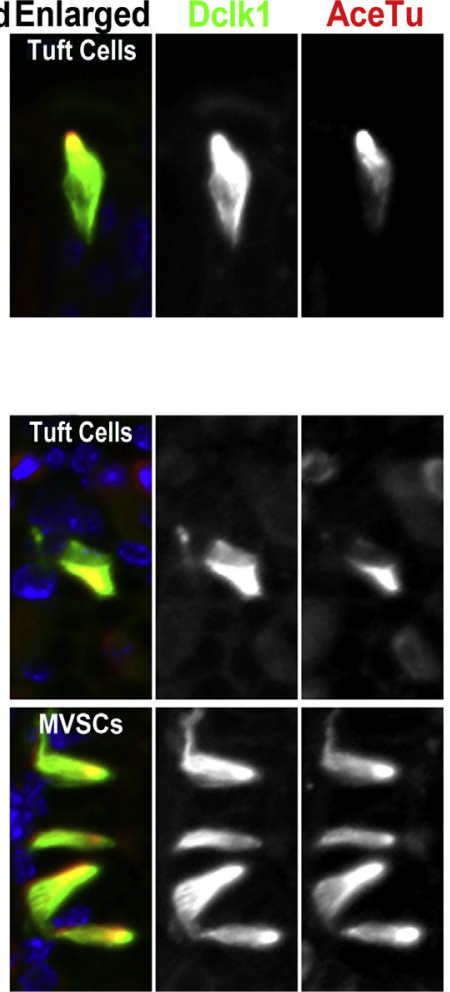

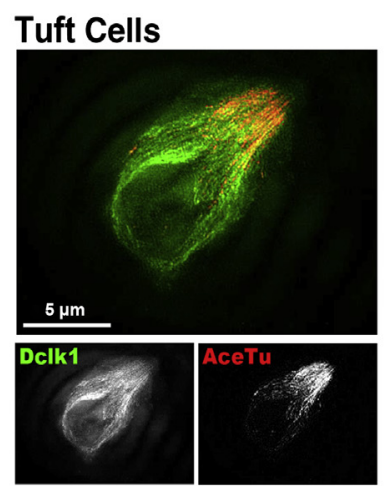

MVSCs

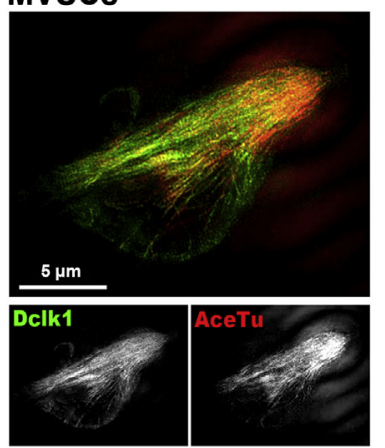

C

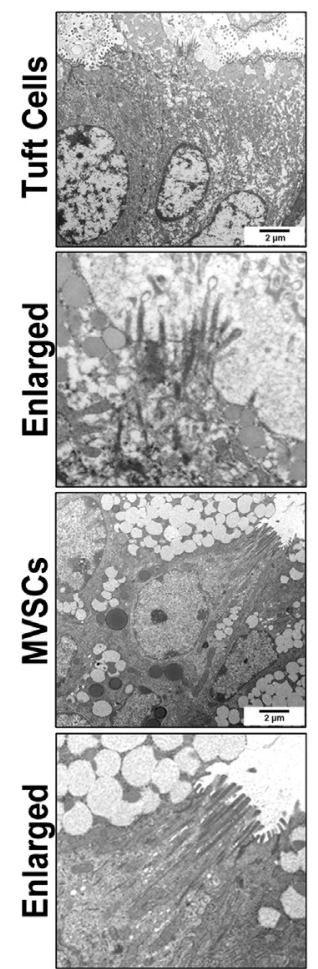

Figure 6 Distinct morphological features of doublecortin-like kinase 1 (Dclk1)-expressing tuft cells and microvillar sensory cells (MVSCs). A: Sections of the oxyntic glands were immunostained with antibodies against Dclk1 (green) and acetylated tubulin (AceTu; red) from an untreated wild-type mouse (normal) or a wild-type mouse treated with L-635 for 3 days (oxyntic atrophy). Boxed regions depict regions enlarged. B: Structured illumination microscopy imaging of Dclk1 and AceTu in an untreated wild-type mouse (normal) and in a wild-type mouse treated with L-635 for 3 days (oxyntic atrophy) shows two distinct patterns of AceTu staining, showing either only apical microtubules (tuft cells) or extended microtubules throughout the cytoplasm (MVSCs). C: Transmission electron microscopy of tuft cells in untreated wild-type mouse stomachs shows typical apical tufts, but the MVSCs in the gastric mucosa with oxyntic atrophy reveal distinct microvilli structure, microtubule bundles extending throughout the cytoplasm, and a decrease in endoplasmic reticulum.

after 7 days of DMP-777 treatment in wild-type mice, $\mathrm{Gast}^{-1-}$ mice showed rapid induction of SPEM after just one dose of DMP-777. ${ }^{12}$ In the fundic glands from Gast $^{-/-}$ mice, the number of Dclk1-expressing cells was similar to wild-type mice (Supplemental Figure S3). Nevertheless, we did not observe any increase of Dclk1-expressing cells with DMP-777 treatment for 14 days in the $\mathrm{Gast}^{-1-}$ mouse stomachs (Figure 4, C, D, F, G and J, and Supplemental Figure S3). This result indicates that the dynamic expansion of Dclk1-expressing tuft cells is dependent on gastrin.

\section{Microvillar Sensory Cells Observed in Acute 0xyntic Atrophy Are Distinct from the Normal Mucosal Tuft Cells}

Given that the expansion of Dclk1-expressing cells is dependent on gastrin and because the cells are dynamically increased in metaplastic mouse models, we next examined whether the Dclk1-expressing cell expansion is associated with proliferating progenitor cells. Two hours before sacrifice, BrdU was administered to mice treated with DMP-777 for 7 and 14 days or recovered for 14 days after 14 days of DMP-777 treatment. Cells positive for BrdU increased 2.5-fold by 7 and 14 days of DMP-777 treatment compared with the untreated mice (Figure 5). However, we did not observe any cells copositive for both Dclk1 and BrdU in either untreated control mice or DMP-777-treated mice. Thus, the increase in Dclk1-expressing cells in the mouse stomachs with acute oxyntic atrophy does not result from proliferation of tuft cells.

We next investigated whether the Dclk1-expressing cells in normal stomachs and the expanded Dclk1-expressing cells in oxyntic atrophy are structurally identical. First, we costained Dclk1-expressing cells with several tuft cell markers, such as acetylated tubulin, Sox9, and phospho$\mathrm{EGFR}^{3,23}$ in untreated wild-type mouse stomachs and stomachs from wild-type mouse treated with L-635 for 3 days (Supplemental Figure S4). Acetylated tubulin-positive cells in both normal mouse stomachs and oxyntic atrophy were copositive for Sox9 and phospho-EGFR.

Interestingly, we noticed the different cellular distribution of acetylated tubulin in tuft cells between wild-type mouse stomachs and in oxyntic atrophy (Figure 6). In the wild-type mouse stomachs, the acetylated tubulin was observed in the apical tufts. However, the acetylated tubulin staining in the Dclk1-expressing cells associated with oxyntic atrophy 

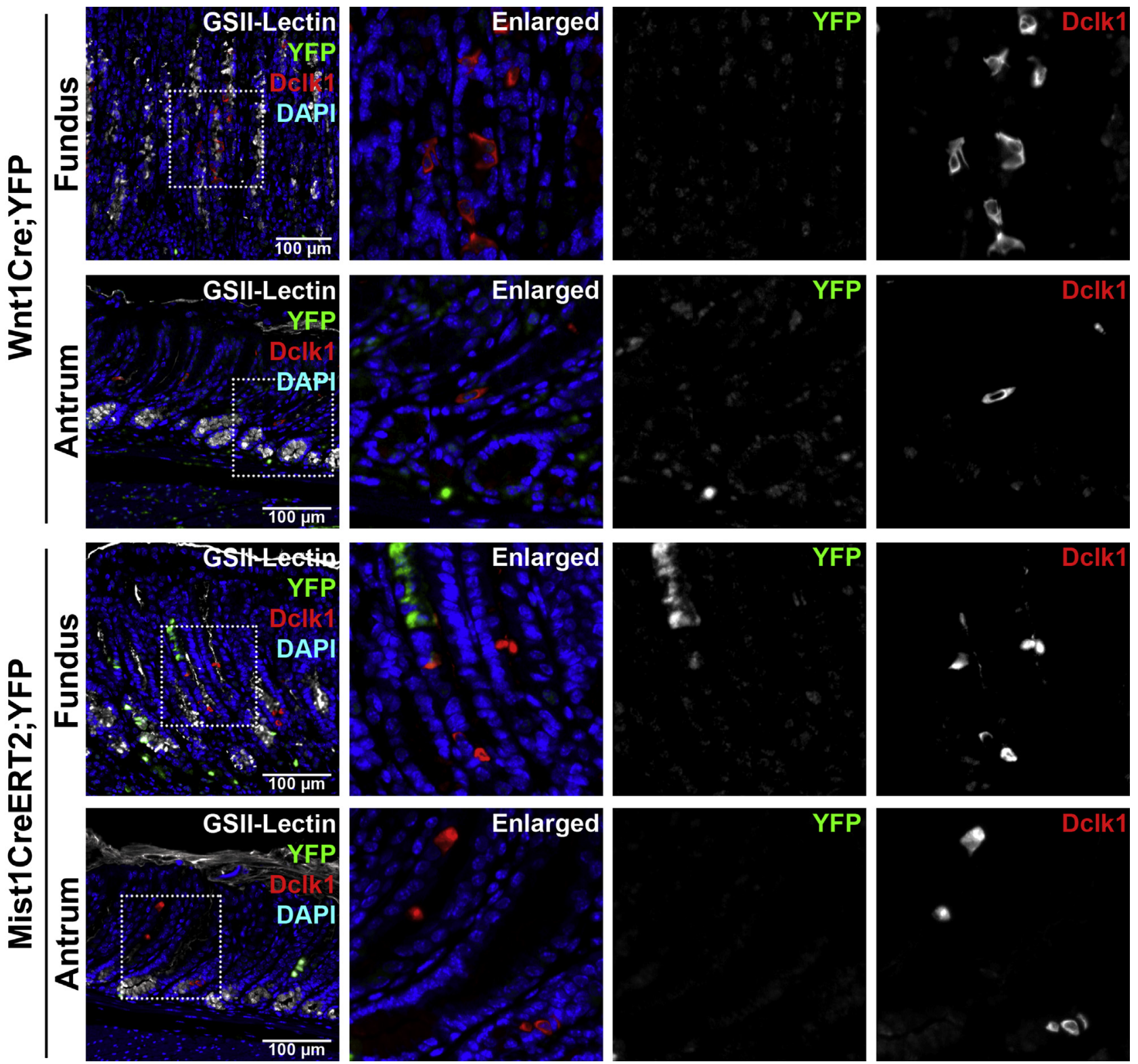

Figure 7 Lineage mapping of doublecortin-like kinase 1 (Dclk1)-expressing cells in Wnt $1^{\text {Cre/ }+} ; R 26 R^{\text {eYFP }}$ mice and Mist $1^{\text {CreERT2/+ }} ; R_{226 R^{\text {eYFP }}}$ mice treated with DMP-777. In $W n t 1^{\text {Cre/ }+} ; R 26 R^{\text {eYFP }}$ mouse stomachs after treatment with DMP-777 for 14 days, yellow fluorescent protein (YFP; green) is occasionally detected in the gastric mucosa, but does not colocalize with Dclk1 (red). In Mist ${ }^{\text {CreERT2/+ }} ;{ }^{2} 26 R^{\text {eYFP }}$ mouse stomachs after treatment with DMP-777 for 14 days, Dclk1 is observed in the YFP-positive oxyntic glands of the fundus, but Dclk1 does not colocalize with YFP. GSII-Lectin (white) stained glands with spasmolytic polypeptide-expressing metaplasia cells. Boxed areas depict regions enlarged.

showed two distinct expression patterns (Figure 6A). In approximately $24 \%$ of Dclk1-expressing cells, acetylated tubulin staining was observed only in the apical tufts and in the other $76 \%$ of Dclk1-expressing cells, acetylated tubulin staining was observed throughout the cytoplasm (Supplemental Figure S5). Only 9\% of the Dclk1expressing cells also showed cytoplasmic acetylated tubulin staining in normal mouse stomachs. We next imaged Dclk1 and acetylated tubulin stained in normal mouse stomachs and after induction of oxyntic atrophy with L-635 using super-resolution fluorescence SIM (Figure 6B). As we observed for the cytoplasmic localization of acetylated tubulin in oxyntic atrophy using conventional microscopy, the microtubules stained for acetylated tubulin extended throughout the cytoplasm, whereas the Dclk1-expressing cells observed in normal mouse stomachs and less frequently in the upper neck gland region in oxyntic atrophy showed acetylated tubulin staining only in apical microtubule bundles.

We further examined tuft cell lineages in normal mouse stomachs and after induction of oxyntic atrophy with L-635 using transmission electron microscopy (Figure 6C). Tuft cells have previously been sub-classified in terms of their ultrastructural morphology, even when the molecular 
characteristics of tuft cells are similar. ${ }^{24}$ Although the tuft cells in wild-type mouse stomachs showed a typical apical brush-like structure, the tuft cells in the fundic mucosa with oxyntic atrophy showed a distinct morphology with more prominent apical microvilli and microtubule bundles extending throughout the cell. Also, the tuft-like cells associated with oxyntic atrophy contained a smaller amount of endoplasmic reticulum, compared with the tuft cells in normal stomach. These data indicated that the expanded Dclk1-expressing tuft-like cells observed after oxyntic atrophy display a distinct apical sensory apparatus and should be designated as microvillar sensory cells (MVSCs) to distinguish them from the normal gastric mucosal tuft cells.

\section{The Dclk1-Expressing Cells Present in Gastric Mucosa} Do Not Originate from Neural Crest Cells, Chief Cells, or Parietal Cells in the Mouse Fundic Mucosa

To examine which lineages of gastric cells might contribute to the Dclk1-expressing cell expansion, we next performed lineage tracing studies by intercrossing several lineage-specific Cre driver mouse lines and two different Cre-inducible reporter mouse lines: either $G t(R O S A) 26 \operatorname{Sor}^{\text {tmISor }}\left(R 26 R^{\text {LacZ }^{2}}\right)$ or ROSA26-eYFP $\left(R 26 R^{\text {YYFP }}\right)$.

The $D c l k 1$ gene is expressed in precursors of neural stem cells. ${ }^{25,26}$ Wnt1 is a crucial signaling molecule involved in neural tube formation during embryogenesis and expressed in the mid-hindbrain isthmus area and in neural crest cells. ${ }^{16}$ Thus, we performed a lineage tracing study using the Wnt1-specific Cre driver mouse strain. We treated $W n t 1^{\text {Crelt }} ; R 26 R^{e Y F P}$ mice with DMP-777 for 14 days to increase the Dclk1-expressing cells. Consistent with previous studies, ${ }^{25,26}$ YFP was detected in the nerve bundles of the submucosa and occasionally observed in the gastric mucosa (Supplemental Figure S6). However, although Dclk1 colocalized in the YFP-positive neural cells in the gastric submucosa, we did not observe any copositive cells for Dclk1 and YFP in the glands of either the gastric fundus or antrum (Figure 7). Therefore, although the Dclk1-expressing cells in the nerves of the submucosa are derived from neural crest cells, the Wnt1-expressing neural crest cells do not produce the Dclk1-expressing cells located in the gastric mucosa.

We next investigated whether the Dclk1-expressing cells are derived from chief cells, because we have previously reported that transdifferentiation of Mist1-expressing chief cells produces SPEM after loss of parietal cells. ${ }^{10} \mathrm{We}$ examined Mist ${ }^{\text {CreERT2/+ }} ; R 26 R^{\text {eYFP }}$ mouse stomachs 10 days after tamoxifen injection (1 mg every other day, three doses) and treated with DMP-777 for 14 days. We observed YFP-positive metaplastic cells derived from the Mist1expressing chief cells in the fundic glands with SPEM (Figure 7). However, no YFP-expressing cells were copositive for Dclk1, indicating that the expansion of Dclk1-expressing cells does not derive from chief cells.

We additionally investigated the possibility of parietal cells as a source of expanded Dclk1-expressing cells in the oxyntic mucosa with or without oxyntic atrophy using an H/K-ATPase-Cre mouse model $\left(\right.$ Atp $\left.4 b^{\text {CreERT2/+ }}\right) .{ }^{27}$ The $A t p 4 b^{\text {CreERT2/+ }}$ mice were treated with three doses of tamoxifen and after 10 days were treated with 3 days of L-635. There was no overlap of YFP lineage tracing with Dclk1 in untreated mice and after 3 days of L-635 treatment, and no parietal cell-lineage tracing Dclk1-expressing cells were observed (Supplemental Figure S7).

\section{Lgr5- and Lrig1-Positive Stem Cells Produce a} Subpopulation of Dclk1-Expressing Cells in the Gastric Mucosa, But Not the Expansion of Fundic Dclk1Expressing Cells Associated with 0xyntic Atrophy

Previous studies have reported that Lgr5-positive stem cells produce the entire compendium of antral glandular lineages. ${ }^{28} \mathrm{We}$ investigated whether Dclk1-expressing cells are derived from Lgr5-positive stem cells in $\operatorname{Lgr5}^{\text {EGFP-IRES-creERT2/+ }} ; R 26 R^{\text {LacZ }}$ mice 10 days after tamoxifen injection $(1 \mathrm{mg}$, three doses). Consistent with our previous study, ${ }^{28}$ only a small population of Lgr5 lineage-traced cells existed in the oxyntic mucosa along the lesser curvature, but $\beta$-galactosidase expression was observed in many antral glands (Figure 8). We observed that several $\beta$-galactosidase-expressing cells were positive for Dclk1 only in the antrum, but not in the fundus. Therefore, the activity of Lgr5-positive stem cells was a source of Dclk1-expressing tuft cells only in the antral mucosa.

We next examined the stem cell activity of Lrig1-expressing cells in the mouse stomach. Lrig1 is a marker of long-lived quiescent stem cells that are present in the intestinal crypt bases, and the Lrig1-positive stem cells show proliferative activity in response to the damage of colonic crypts. ${ }^{20}$ Thus, we examined Lrig $1^{\text {CreERT2/+ }} ; R 26 R^{\text {PYFP }}$ mouse stomachs 10 days after tamoxifen injection ( $2 \mathrm{mg}$, one dose). YFP was observed in both fundic and antral mucosal cells (Figure 7). Also, we found cells copositive for YFP and Dclk1 in both the fundus and antrum. These results suggested that some of the Dclk1-expressing tuft cells were derived from Lrig1-expressing stem cells. We next treated the $L$ rig ${ }^{\text {CreERT2/+ }} ; R 26 R^{\text {eYFP }}$ mice with DMP-777 for 14 days to test whether Lrig1-positive stem cells contribute to the expansion of Dclk1-expressing cells induced by acute oxyntic atrophy. Although DMP-777 treatment led to the expansion of Dclk1-expressing cells in fundic glands with SPEM, the number of YFP colocalized cells did not increase (Figure 8). These results suggested that Lrig1-positive stem cells produce the Dclk1-expressing tuft cells in the normal fundus and antrum, but the Lrig1-positive stem cells do not contribute to expansion of MVSCs.

\section{Discussion}

The normal gastric mucosa is composed of a heterogeneous group of epithelial cell lineages responsible for the secretion 


of mucins, pepsinogen, intrinsic factor, hydrochloride, and several endocrine hormones and growth factors. Gastric tuft cells detected by Dclk1 are distinct from other epithelial cell lineages in the stomach. Tuft cells are scattered throughout both the gastric fundic and antral mucosa ${ }^{9}$ and are distinguished by their unique luminal tuft labeled with acetylated tubulin and Dclk1. ${ }^{1}$ Although tuft cells in many organs are considered a type of solitary chemosensory cell that expresses taste receptors for chemical transduction, ${ }^{5}$ the function of gastric tuft cells remains unknown.

Herein, we evaluated the dynamic changes of Dclk1expressing cells in the mouse gastric fundic mucosa associated with oxyntic atrophy. We have identified a novel subtype of Dclk1-expressing cells, MVSCs, which display a distinct apical microstructure that was demonstrable in both transmission electron microscopy and superresolution SIM fluorescence imaging. MVSCs were present only after oxyntic atrophy. Loss of parietal cells in the oxyntic glands leads to global changes in the mucosa of the gastric fundus, including chief cell transdifferentiation into SPEM. ${ }^{10,29}$ The MVSCs were not only observed in association with SPEM without inflammation in DMP-777-treated mice, but also with SPEM associated with inflammation in L-635-treated and H. felis-infected mice. The Dclk1expressing MVSCs increased in invasive metaplastic fundic glands of $\mathrm{Areg}^{-1-}$ mice, in metaplastic regions of INS/GAS mice, and in gastric tumors of Smad3-deficient mice. ${ }^{9}$ Nevertheless, in the models of acute oxyntic atrophy, the increase in MVSCs was rapidly reversed to normal levels after cessation of either DMP-777 or L-635 treatment for 14 days. The results indicate that the population of sensory cells in the gastric fundus is highly dynamic in response to parietal cell loss driven by loss of acid secretion and subsequent elevations of gastrin. Although the exact role of the MVSCs in the setting of mucosal injury is not clear, the general role of tuft cell lineages in molecular sensing suggests that these transient sensory cells may be involved in identifying molecules released in the damaged mucosa. The loss of these cells from the mucosa after re-establishment of normal oxyntic mucosa lineages may then reflect a cessation of particular sensory cues.

The present results demonstrate that Dclk1-expressing MVSCs increased in the fundic mucosa after loss of parietal cells. The parietal cells secrete gastric acid and several mucosal growth factors, such as transforming growth factor- $\alpha, \mathrm{AR}$, heparin-binding EGF-like growth factor, and sonic hedgehog, ${ }^{30-33}$ and the changes of these mucosal growth factors by the loss of parietal cells may have an influence on the expansion of Dclk1-expressing cells. Gastrin levels are elevated in mice with oxyntic atrophy, ${ }^{34}$ and we observed herein that the dynamic changes of Dclk1-expressing MVSCs were accompanied with conditions that promote elevated gastrin levels. The number of Dclk1-expressing cells in the oxyntic glands of $\mathrm{Gast}^{-/-}$ mice was similar to that in wild-type mouse stomachs (Supplemental Figures S2 and S3), indicating that gastrin is not required for the presence of Dclk1-expressing tuft cells in normal mouse stomachs. Although our previous studies showed that gastrin deficiency leads to a rapid induction of SPEM in $\mathrm{Gast}^{-1-}$ mice, ${ }^{12}$ the fundic Dclk1-expressing cells did not significantly increase in Gast $^{-1}$ mice after DMP treatment for 3, 7, and 14 days. Therefore, the MVSCs, as reflected in the expansion of fundic Dclk1-expressing cells in the setting of acute oxyntic atrophy, require gastrin as a critical driving force. More important, we did not observe any changes in tuft cell numbers in the antrum in association with oxyntic atrophy in any of the models. A previous study has reported increased tuft cell numbers in Gast $^{-/-}$mice, ${ }^{35}$ but these cells appear to be associated with antral tumors in older animals. We have similarly observed many tuft cells in invasive antral lesions in 18-month-old $\mathrm{Gast}^{-1-}$ mice (Supplemental Figure S8).

The Dclkl gene is expressed in migrating or post-mitotic neurons and in radial glia cells as precursors of neural stem cells. ${ }^{7,25}$ Given that the expression of Dclk1 is observed in early neurogenesis and later in the gut, we examined whether the Dclk1-expressing cells are derived from neural crest stem cells using $\mathrm{Wnt}^{\mathrm{Cre} / \mathrm{t}}$ mice. The Dclk1-expressing nerve cells in the submucosa were derived from Wnt1 lineage-traced cells. However, the Dclk1-expressing cells in the gastric mucosa did not colocalize with any Wnt1 lineage-traced cells. Thus, the Dclk1-expressing cells in the gastric mucosa are not derived from neural stem cells. In oxyntic atrophy, parietal cell loss initiates transdifferentiation of mature Mist1-expressing chief cells into SPEM. ${ }^{12,36}$ However, our lineage tracing study using Mist ${ }^{\text {CreERT2/+ }}$ mice with acute oxyntic atrophy showed that the Mist1 lineage-traced cells did not account for the expanded Dclk1-expressing cells (Figure 7). The Mist1 lineage-traced cells also did not produce the Dclk1-expressing cells in the normal oxyntic glands (data not shown). Thus, Mist1expressing chief cells are not a source of the Dclk1-expressing cells.

Although our data suggest that neural crest progenitors, chief cells, and parietal cells are not the source of Dclk1-expressing tuft cells in the gastric mucosa, Dclk1-expressing tuft cells in the normal gastric mucosa were traced from the stem cell markers,

\footnotetext{
Figure 8 Lineage mapping of doublecortin-like kinase 1 (Dclk1)-expressing cells in Lgr5 $^{\text {EGFP-IRES-creERT2/+ }} ; R 26 R^{\text {LacZ }}$ mice and $L$ rig $1^{\text {CreERT2/+ }} ; R 26 R^{\text {eYFP }}$ mice. In Lgr5 ${ }_{\text {EGFP-IRES-creERT2/+ }} ; R 26 R^{\text {LacZ }}$ mouse stomachs 10 days after tamoxifen $(1 \mathrm{mg}$, four doses), $\beta$-galactosidase ( $\beta$-gal; green) is detected in the antral glands and Dclk1 (red) colocalizes with $\beta$-gal in several cells. In $\operatorname{Lrig}_{1}{ }^{\text {CreERT2/+ }} ; R 26 R^{\text {eYFP }}$ mouse stomachs, copositive cells for Dclk1 and yellow fluorescent protein (YFP) are observed in both fundic and antral glands. In Lrig $1^{\text {CreERT2/+ }} ; R_{26 R^{\text {eYFP }}}$ mouse stomachs treated with DMP-777 for 14 days, copositive cells for Dclk1 (red) and YFP (green) are observed in both fundic and antral glands. However, the number of copositive cells does not increase in the fundic glands with spasmolytic polypeptide-expressing metaplasia (SPEM), compared with normal glands of the fundus. GSII-Lectin (white) stained glands with SPEM cells. Boxed areas depict regions enlarged.
} 
Lgr5, and Lrig1. ${ }^{19,20}$ The Dclk1-expressing cells in the antral glands colabeled with both Lgr5- and Lrig1 lineage-traced cells, but the Dclk1-expressing cells in the normal oxyntic glands colocalized only with Lrig1 lineage-traced cells (Figure 8). Although the Lrig1-positive stem cells can produce the Dclk1expressing cells in normal oxyntic glands, the MVSCs after acute oxyntic atrophy were not derived from the Lrig1 lineagetraced cells. These data consequently indicate that the expansion of MVSCs is derived from other sources, such as endocrine cells (eg, electrochemiluminescence or somatostatin cells) or unrecognized gastric stem cells. Unfortunately, lineage mapping mouse lines for electrochemiluminescence cells and somatostatin cells are not presently available.

In summary, the Dclk1-expressing tuft cell is a rare population among cell lineages of the normal gastric fundus derived in part from Lrig1-expressing stem cells. The MVSC population in the fundic mucosa is increased in response to oxyntic atrophy, and an elevated gastrin level is necessary for the dynamic changes in Dclk1-expressing cells. The expansion of the MVSCs is sustained in the metaplastic mucosa, but is readily reversible on resolution of parietal cell loss. Several types of tuft-like sensory cells defined by different morphologies are present in taste buds and olfactory epithelium. ${ }^{24,37,38}$ However, it is not clear whether the morphological differences reflect different stages of tuft cell maturation or different cell origins. Our study suggests that the different morphological characteristics of MVSCs compared with normal resident tuft cells may reflect a distinct origin from the normal tuft cells. Further studies will be required to determine the precise origin and fate of MVSCs associated with oxyntic atrophy.

\section{Acknowledgments}

E.C. designed and performed experiments, compiled figures, and wrote the manuscript; C.P.P., L.A.L., and V.G.W. performed experiments and reviewed the manuscript; J.A.W. designed and performed experiments and reviewed the manuscript; J.R.G. designed experiments and edited figures and the manuscript; and K.T.N. designed and performed experiments, compiled figures, and edited the manuscript.

\section{Supplemental Data}

Supplemental material for this article can be found at http://dx.doi.org/10.1016/j.ajpath.2015.04.009.

\section{References}

1. Saqui-Salces M, Keeley TM, Grosse AS, Qiao XT, El-Zaatari M, Gumucio DL, Samuelson LC, Merchant JL: Gastric tuft cells express DCLK1 and are expanded in hyperplasia. Histochem Cell Biol 2011, 136:191-204

2. Nabeyama A, Leblond CP: "Caveolated cells" characterized by deep surface invaginations and abundant filaments in mouse gastro-intestinal epithelia. Am J Anat 1974, 140:147-165
3. Gerbe F, Legraverend C, Jay P: The intestinal epithelium tuft cells: specification and function. Cell Mol Life Sci 2012, 69:2907-2917

4. Sato A: Tuft cells. Anat Sci Int 2007, 82:187-199

5. Hofer D, Drenckhahn D: Identification of the taste cell G-protein, alpha-gustducin, in brush cells of the rat pancreatic duct system. Histochem Cell Biol 1998, 110:303-309

6. Gerbe F, van Es JH, Makrini L, Brulin B, Mellitzer G, Robine S, Romagnolo B, Shroyer NF, Bourgaux JF, Pignodel C, Clevers H, Jay P: Distinct ATOH1 and Neurog3 requirements define tuft cells as a new secretory cell type in the intestinal epithelium. J Cell Biol 2011, 192:767-780

7. Friocourt G, Liu JS, Antypa M, Rakic S, Walsh CA, Parnavelas JG: Both doublecortin and doublecortin-like kinase play a role in cortical interneuron migration. J Neurosci 2007, 27:3875-3883

8. Nakanishi Y, Seno H, Fukuoka A, Ueo T, Yamaga Y, Maruno T, Nakanishi N, Kanda K, Komekado H, Kawada M, Isomura A, Kawada K, Sakai Y, Yanagita M, Kageyama R, Kawaguchi Y, Taketo MM, Yonehara S, Chiba T: Dclk1 distinguishes between tumor and normal stem cells in the intestine. Nat Genet 2013, 45:98-103

9. Nam KT, O’Neal R, Lee YS, Lee YC, Coffey RJ, Goldenring JR: Gastric tumor development in Smad3-deficient mice initiates from forestomach/glandular transition zone along the lesser curvature. Lab Invest 2012, 92:883-895

10. Nam KT, Lee HJ, Sousa JF, Weis VG, O'Neal RL, Finke PE, RomeroGallo J, Shi G, Mills JC, Peek RM Jr, Konieczny SF, Goldenring JR: Mature chief cells are cryptic progenitors for metaplasia in the stomach. Gastroenterology 2010, 139:2028-2037.e9

11. Goldenring JR, Ray GS, Coffey RJ, Meunier PC, Haley PJ, Barnes TB, Car BD: Reversible drug-induced oxyntic atrophy in rats. Gastroenterology 2000, 118:1080-1093

12. Nomura S, Yamaguchi H, Ogawa $M$, Wang TC, Lee JR, Goldenring JR: Alterations in gastric mucosal lineages induced by acute oxyntic atrophy in wild-type and gastrin-deficient mice. Am J Physiol Gastrointest Liver Physiol 2005, 288:G362-G375

13. Wang TC, Dangler CA, Chen D, Goldenring JR, Koh T, Raychowdhury R, Coffey RJ, Ito S, Varro A, Dockray GJ, Fox JG: Synergistic interaction between hypergastrinemia and Helicobacter infection in a mouse model of gastric cancer. Gastroenterology 2000, 118:36-47

14. Nam KT, Lee HJ, Mok H, Romero-Gallo J, Crowe JE Jr, Peek RM Jr, Goldenring JR: Amphiregulin-deficient mice develop spasmolytic polypeptide expressing metaplasia and intestinal metaplasia. Gastroenterology 2009, 136:1288-1296

15. Fox JG, Wang TC, Rogers AB, Poutahidis T, Ge Z, Taylor N, Dangler CA, Israel DA, Krishna U, Gaus K, Peek RM Jr: Host and microbial constituents influence Helicobacter pylori-induced cancer in a murine model of hypergastrinemia. Gastroenterology 2003, 124: $1879-1890$

16. Danielian PS, Muccino D, Rowitch DH, Michael SK, McMahon AP. Modification of gene activity in mouse embryos in utero by a tamoxifen-inducible form of Cre recombinase. Curr Biol 1998, 8: 1323-1326

17. Soriano P: Generalized lacZ expression with the ROSA26 Cre reporter strain. Nat Genet 1999, 21:70-71

18. Shi G, Zhu L, Sun Y, Bettencourt R, Damsz B, Hruban RH, Konieczny SF: Loss of the acinar-restricted transcription factor Mist1 accelerates Kras-induced pancreatic intraepithelial neoplasia. Gastroenterology 2009, 136:1368-1378

19. Barker N, van Es JH, Kuipers J, Kujala P, van den Born M, Cozijnsen M, Haegebarth A, Korving J, Begthel H, Peters PJ, Clevers H: Identification of stem cells in small intestine and colon by marker gene Lgr5. Nature 2007, 449:1003-1007

20. Powell AE, Wang Y, Li Y, Poulin EJ, Means AL, Washington MK, Higginbotham JN, Juchheim A, Prasad N, Levy SE, Guo Y, Shyr Y, Aronow BJ, Haigis KM, Franklin JL, Coffey RJ: The pan-ErbB negative regulator Lrig1 is an intestinal stem cell marker that functions as a tumor suppressor. Cell 2012, 149:146-158 
21. Srinivas S, Watanabe T, Lin CS, William CM, Tanabe Y, Jessell TM, Costantini F: Cre reporter strains produced by targeted insertion of EYFP and ECFP into the ROSA26 locus. BMC Dev Biol 2001, 1:4

22. Ohtsu H, Tanaka S, Terui T, Hori Y, Makabe-Kobayashi Y, Pejler G, Tchougounova E, Hellman L, Gertsenstein M, Hirasawa N, Sakurai E, Buzas E, Kovacs P, Csaba G, Kittel A, Okada M, Hara M, Mar L, Numayama-Tsuruta K, Ishigaki-Suzuki S, Ohuchi K, Ichikawa A, Falus A, Watanabe T, Nagy A: Mice lacking histidine decarboxylase exhibit abnormal mast cells. FEBS Lett 2001, 502:53-56

23. Delgiorno KE, Hall JC, Takeuchi KK, Pan FC, Halbrook CJ, Washington MK, Olive KP, Spence JR, Sipos B, Wright CV, Wells JM, Crawford HC: Identification and manipulation of biliary metaplasia in pancreatic tumors. Gastroenterology 2014, 146:233-244.e5

24. Tizzano M, Finger TE: Chemosensors in the nose: guardians of the airways. Physiology (Bethesda) 2013, 28:51-60

25. Vreugdenhil E, Kolk SM, Boekhoorn K, Fitzsimons CP, Schaaf M, Schouten T, Sarabdjitsingh A, Sibug R, Lucassen PJ: Doublecortinlike, a microtubule-associated protein expressed in radial glia, is crucial for neuronal precursor division and radial process stability. Eur J Neurosci 2007, 25:635-648

26. Shu T, Tseng HC, Sapir T, Stern P, Zhou Y, Sanada K, Fischer A, Coquelle FM, Reiner O, Tsai LH: Doublecortin-like kinase controls neurogenesis by regulating mitotic spindles and $\mathrm{M}$ phase progression. Neuron 2006, 49:25-39

27. Xiao C, Feng R, Engevik AC, Martin JR, Tritschler JA, Schumacher M, Koncar R, Roland J, Nam KT, Goldenring JR, Zavros Y: Sonic Hedgehog contributes to gastric mucosal restitution after injury. Lab Invest 2013, 93:96-111

28. Nam KT, O’Neal RL, Coffey RJ, Finke PE, Barker N, Goldenring JR: Spasmolytic polypeptide-expressing metaplasia (SPEM) in the gastric oxyntic mucosa does not arise from Lgr5-expressing cells. Gut 2012, 61:1678-1685

29. Weis VG, Goldenring JR: Current understanding of SPEM and its standing in the preneoplastic process. Gastric Cancer 2009, 12:189-197
30. Abe S, Sasano H, Katoh K, Ohara S, Arikawa T, Noguchi T, Asaki S, Yasui W, Tahara E, Nagura H, Toyota T: Immunohistochemical studies on EGF family growth factors in normal and ulcerated human gastric mucosa. Dig Dis Sci 1997, 42:1199-1209

31. Beauchamp RD, Barnard JA, McCutchen CM, Cherner JA, Coffey RJ Jr: Localization of transforming growth factor alpha and its receptor in gastric mucosal cells: implications for a regulatory role in acid secretion and mucosal renewal. J Clin Invest 1989, 84:1017-1023

32. Murayama Y, Miyagawa J, Higashiyama S, Kondo S, Yabu M, Isozaki K, Kayanoki Y, Kanayama S, Shinomura Y, Taniguchi N, Matsuzawa Y: Localization of heparin-binding epidermal growth factor-like growth factor in human gastric mucosa. Gastroenterology 1995, 109:1051-1059

33. Stepan V, Ramamoorthy S, Nitsche H, Zavros Y, Merchant JL, Todisco A: Regulation and function of the sonic hedgehog signal transduction pathway in isolated gastric parietal cells. J Biol Chem 2005, 280:15700-15708

34. Korman MG, Strickland RG, Hansky J: Serum gastrin in chronic gastritis. Br Med J 1971, 2:16-18

35. Zavros Y, Eaton KA, Kang W, Rathinavelu S, Katukuri V, Kao JY, Samuelson LC, Merchant JL: Chronic gastritis in the hypochlorhydric gastrin-deficient mouse progresses to adenocarcinoma. Oncogene 2005, 24:2354-2366

36. Ramsey VG, Doherty JM, Chen CC, Stappenbeck TS, Konieczny SF, Mills JC: The maturation of mucus-secreting gastric epithelial progenitors into digestive-enzyme secreting zymogenic cells requires Mist1. Development 2007, 134:211-222

37. Yee CL, Yang R, Bottger B, Finger TE, Kinnamon JC: "Type III" cells of rat taste buds: immunohistochemical and ultrastructural studies of neuron-specific enolase, protein gene product 9.5, and serotonin. J Comp Neurol 2001, 440:97-108

38. Asan E, Drenckhahn D: Immunocytochemical characterization of two types of microvillar cells in rodent olfactory epithelium. Histochem Cell Biol 2005, 123:157-168 